\title{
Barriers to physical activity during the COVID-19 pandemic in adults: a cross-sectional study
}

\author{
Breno Quintella Farah ${ }^{1,2}$ (1) $\cdot$ Wagner Luiz do Prado ${ }^{3} \cdot$ Neal Malik $^{4} \cdot$ Mara Cristina Lofrano-Prado ${ }^{5}$. \\ Paulo Henrique de Melo ${ }^{2}$. Joao Paulo Botero ${ }^{6} \cdot$ Gabriel Grizzo Cucato $^{7} \cdot$ Marilia de Almeida Correia $^{8}$. \\ Raphael Mendes Ritti-Dias ${ }^{9}$
}

Received: 6 July 2020 / Accepted: 1 December 2020 / Published online: 27 March 2021

(c) The Author(s), under exclusive licence to Springer-Verlag Italia S.r.l., part of Springer Nature 2021

\begin{abstract}
Social isolation due to the coronavirus disease 2019 (COVID-19) pandemic has reduced physical activity levels in both men and women. The identification of barriers to physical activity may assist in developing strategies to increase levels of physical activity during this pandemic. The study aim was identify the barriers to regular participation in physical during the COVID19 pandemic in Brazilian adults. This cross-sectional study included 1570 [56.6\% women; aged: 39.1 (37.7-40.7) years old] in social isolation due COVID-19. Barriers to physical activity were obtained using the validated questionnaires. "Laziness and fatigue" (50.2\%), "lack of motivation" (31.2\%), "lack of appropriate facilities/equipment/space" (17.4\%), and "lack of time" $(13.0 \%)$ were the barriers most prevalent in the study. Lack of motivation $(\mathrm{OR}=1.49 ; 95 \% \mathrm{CI}=1.19-1.86)$ and lack of appropriate facilities/equipment/space $(\mathrm{OR}=2.11 ; 95 \% \mathrm{CI}=1.57-2.83)$ were most associated with impacting physical activity levels due to the COVID-19, independent of sex, age, education level, days of social isolation and status weight. In conclusion, personal barriers to physical activity are common between both sexes, with lack of motivation and lack of appropriate facilities/equipment/space most associated with a decreased level of physical activity due to the COVID-19 pandemic.
\end{abstract}

Keywords Physical activity $\cdot$ Barriers $\cdot$ Adults $\cdot$ Coronavirus infections

Breno Quintella Farah

brenofarah@hotmail.com

1 Federal Rural University of Pernambuco, Rua Dom Manuel de Medeiros, s/n Dois Irmãos, Recife, PE 52171-900, Brazil

2 Graduate Program in Physical Education, Federal University of Pernambuco (UFPE), Recife, Brazil

3 Department of Kinesiology, California State University San Bernardino, San Bernardino, USA

4 Department of Health Science and Human Ecology, California State University San Bernardino, San Bernardino, CA, USA

5 California, USA

6 Human Movement Science and Rehabilitation Graduation Program, Sao Paulo Federal University, Santos, São Paulo, Brazil

7 Department of Sport, Exercise and Rehabilitation, Northumbria University, Newcastle upon Tyne, England, UK

8 Graduated Program in Medicine, Universidade Nove de Julho, São Paulo, Brazil

9 Graduated Program in Rehabilitation Sciences, Universidade Nove de Julho, São Paulo, Brazil

\section{Introduction}

Social isolation is being promoted as a means to reduce the spread of Coronavirus 2019 (COVID-19) [1]. However, social isolation may lead to a subsequent reduction in physical activity levels [2-4], that can bring several consequences to health, particularly the immune, neuromuscular, cardiorespiratory and metabolic, systems, in addition to being associated with reduced incidence of cancer, cardiovascular disease, diabetes of type 2 and allcause and specific mortality [5-10].

Aware of the consequence of physical inactivity several institutions, such as World Health Organization [11] and American College of Sports Medicine [12], have recommended the physical activity practice. However, several studies have reporting increases in physical inactivity during COVID-19 in different countries [13, 14], indicating difficulties in follow the recommendations to stay active during this period.

The identification of barriers to physical activity is important point when developing interventions to promote 
physical activity [15-17]. Among adults, lack of time, social influence and lack of motivation are frequently reported barriers to regular participation in physical activity $[15,18-20]$. Given these unprecedented times due to the COVID-19 pandemic, lifestyle habits have been dramatically altered $[13,14]$. It is plausible that barriers to physical activity may have changed due social isolation.

Until now (October 2020), no study has been identified at Medline database that investigated the barriers to physical activity in people in social isolation, which would allow the development of specific strategies to increase the physical activity level of the population during social isolation and consequently improve the health indicators $[10,21]$. Thus, the aim of the present study was identify the barriers to regular participation in physical during the COVID-19 pandemic in Brazilian adults.

\section{Methods}

\section{Study design, sample and ethics}

This cross-sectional study was conducted in line with the STROBE checklist [22]. A survey was conducted in Brazil between May 5th and May 17th, 2020. Participants were invited through social media (Facebook, Twitter, Whatsapp and Instagram) to answer a structured electronic questionnaire. The inclusion criteria were: (a) adults $\geq 18$ years old of both sexes; (b) participate in regular physical activity prior to the COVID-19 pandemic (it was asked "Were you engaged in this physical activity before the COVID-19 pandemic?" possible answers: "yes" and "no"), and; (c) complete all responses within the survey. Similar procedures have been used by recent studies [23-25].

This study was approved by the institution's Ethics Committee before data collection (\#30890220.4.0000.5511 approved on May 1st 2020). Prior to the survey, respondents were asked to provide informed consent. Data were collected anonymously and only those that provided consent were included in the analysis. All procedures followed national legislation and the Declaration of Helsinki of 1964 (revised in 2013).

\section{Procedures}

After approval by the ethics committee, a questionnaire using Google Forms was sent to the participants. Data were then transferred to an MS Excel 2019 spreadsheet (Redmond, WA, USA) for further analysis. The survey consisted of 70 questions presented in seven domains: (a) personal information; (b) COVID-19 personal care; (c) physical activity; (d) eating behavior; (e) overall health behavior; (f) mental health; (g) overall health. The instrument was developed for senior researchers with $\mathrm{PhD}$ in different areas (public health, science, nutrition, physiology, human movement science, neuroscience and behavior), which is common in clinical practice [26-28]. It was based in many questionnaires $[15,29-32]$ and put together as one 70 questions instrument referenced in each domain. Questions related to the COVID-19 pandemic were created based on face validity. Given that some domains have not related to the physical activity level or barriers, we used only the domains: (a) personal information, (c) physical activity, and (e) overall health behavior to answer the objective of the present study. Following we present the questions used in the present analysis.

\section{Personal information and overall health behavior}

Information about sex ("woman" or "man"), date of birth (DD/MM/YYYY), type of residence ("house" or "apartment"), educational level ("elementary", "high school", "undergraduate", and "graduate"), and days of social isolation (open question), were obtained.

Smoker (yes or no), alcohol consumption (yes or no) and self-reported chronic diseases (open question) were obtained. Participants anthropometric variables were assessed by selfreport of weight $(\mathrm{kg})$ and height $(\mathrm{m})$, and body mass index (BMI) was calculated by dividing body weight by squared height. Previous studies showed height and weight are commonly self-reported in population health and useful tool for estimating the prevalence of overweight and obesity [33]. Overweight was defined as a BMI $\geq 25.0 \mathrm{~kg} / \mathrm{m}^{2}$.

\section{Physical activity}

\section{Physical activity habits}

To assess physical activity habits, participants were asked about: (a) how many times are you exercising a week? (possible answers: none to seven days a week); (b) for how long are you exercising? (possible answers: "none"; "less than 30 min"; "between 30 and 60 min", and; "more than 60 min"); (c) for how long have you engaged in this physical activity? (possible answer: "less than 1 month"; "between 1 and 3 months"; "between 3 and 6 months"; "more than 6 months", and; "I am not exercising"); (d) What is the intensity of the physical activity? (possible answers: "lowi.e. to bathe, to shave, to drive, wash the dishes, make the bed"; "medium/moderate-i.e. gardening, play volleyball, water aerobics, pedal, brisk walking"; "high-i.e. climb stairs, swimming, jump rope, play soccer, running", and; "I am not exercising"). (e) What type of exercise are you doing? (possible answers: "walking/jogging"; "resistance 
training"; "core exercise"; "I am not exercising"; “othersopen question".

Based on these responses, time spent during each exercise session during the week was multiplied by the number of days spent exercising each week. Those that reached $150 \mathrm{~min}$ or more of moderate-vigorous physical activity (MVPA) were considered, "physically active" whereas those that fell below this threshold were classified as "inactive" [34].

\section{Impact on physical activity level due to COVID-19- outcome}

The impact COVID-19 on physical activity level was assessed through the question: "How much has the COVID19 pandemic interfered with your daily physical activity habits?" The subjects were grouped into the following categories: "No" (if their response was either "none" or "a little") and "Yes" (if they indicated "a lot").

\section{Barriers to physical activity—predictors}

Personal and environmental barriers to physical activity were obtained using a validated questionnaire for adults [citation?], elderly [16], and clinical populations [15, 18]. From the list of the barriers, the participant should mark all that applied for them. Personal barriers included: "laziness and fatigue (tiredness, physical exhaustion)", "lack of motivation", "lack of time", "lack of partner", "pain, injury", "I am not able to", "I have no way to commute for exercising", "It is not fun", "need to relax and rest", "lack of money", "lack of competence", "fear of injuries", "lack of support", "I do not understand why it is important" and "body shame". Environmental barriers included: "due to the COVID-19 pandemic", "lack of appropriate facilities/equipment/space" and "weather".

\section{Statistical analysis}

All statistical analyses were made using the Statistical Package for the Social Sciences software (SPSS/PASW) version 20 (IBM Corp, New York, USA). Frequencies and means (95\% confidence interval-95\% CI) were used for descriptive analysis. The chi-square test was used to compare the prevalence of barriers to physical activity between men and women.

Binary logistic regression was used to analyze the relationship between barriers to physical activity and impact on physical activity due to the COVID-19 pandemic. This model was adjusted for common confounders (sex, age, education level and overweight), type of residence and number of days spent in social isolation. To this end, only barriers with a prevalence greater than $10 \%$ were analyzed. The results were presented in Odds Ratio (OR) and 95\% CI.
Multicollinearity analysis was performed assuming variance inflation factors (VIF) less than five and tolerance below 0.20. The Hosmer-Lemeshow test was used to assess the model's goodness-of-fit. The significance level was set at $p<0.05$ for all analyses.

\section{Results}

From the 1895 subjects enrolled in the present study, three did not respond to the gender identification question and 322 did not practice physical activity before the pandemic. Therefore, the final sample included 1570 respondents. Table 1 shows the general characteristics, comorbid conditions, anthropometric and lifestyle habits variables of subjects.

Physically inactive was present in 71.3 and $61.2 \%$ felt an impact on physical activity level during the COVID-19 pandemic. Table 2 shows the barriers to physical activity in men and women. "Laziness and fatigue", "lack of motivation", "lack of appropriate facilities/equipment/space", and "lack of time" were the barriers most prevalent in the study among both sexes. Compared to men, women more often reported "lack of appropriate facilities/equipment/space" as a barrier $(p=0.007)$.

Tables 3 shows the association between barriers to physical activity and its impact on physical activity level due to COVID-19. Lack of motivation (OR $=1.49 ; 95 \%$ $\mathrm{CI}=1.19-1.86)$ and lack of appropriate facilities/equipment/ space $(\mathrm{OR}=2.11 ; 95 \% \mathrm{CI}=1.57-2.83)$ were most associated with impacting physical activity levels due to the COVID19 , independent of sex, age, education level, days of social isolation and status weight. In this sense, lack of motivation increases the likelihood of impact on physical activity level during the COVID-19 pandemic by $49 \%$, whereas the lack of appropriate facilities/equipment/space increases it by $111 \%$.

\section{Discussion}

The aim of the present study was identify the barriers to regular participation in physical during the COVID-19 pandemic in Brazilian adults. The main results of this study were: (a) "laziness and fatigue", "lack of motivation", "lack of appropriate facilities/equipment/space", and "lack of time" were the barriers most reported during social isolation; (b) "lack of motivation" and "lack of appropriate facilities/equipment/space" were associated with impacting physical activity levels due to the COVID-19, independently of sex, age, education level, days of social isolation and status weight.

Social isolation has been identified as a crucial step in reducing the spread of COVID-19 [1]. However, this 
Table 1 General characteristics, anthropometric and lifestyle habits variables of subjects included in this study $(n=1570)$

\begin{tabular}{ll}
\hline Variables & Values \\
\hline Age (years) & $39.1(37.7-40.7)$ \\
Social isolation (days) & $43.5(42.8-44.2)$ \\
Self-reported weight $(\mathrm{kg})$ & $73.6(72.9-74.4)$ \\
Self-reported height $(\mathrm{m})$ & $1.69(1.68-1.69)$ \\
Body mass index $\left(\mathrm{kg} / \mathrm{m}^{2}\right)$ & $25.8(25.8-26.0)$ \\
Sex $(\%$ women) & 56.6 \\
Educational level (\% low) & $\mathrm{a}$ \\
Smoker (\% yes) & 8.1 \\
Alcoholic beverages (\% yes) & 5.4 \\
Physically inactive (\% yes) & 65.7 \\
Overweight (\% yes) & 67.7 \\
Hypertension (\% yes) & 49.0 \\
Diabetes mellitus (\% yes) & 9.2 \\
Dyslipidemia (\% yes) & 1.3 \\
Cardiac disease (\% yes) & 8.6 \\
Depression (\% yes) & 1.4 \\
Asthma (\% yes) & 4.5 \\
Arthrosis (\% yes) & 6.1 \\
\hline
\end{tabular}

Continues data are present as mean (95\% confidence interval) and categorical data in frequency

practice may have unintended negative consequences leading increase in sedentary behavior and reduction in physical activity levels $[13,14,35]$. Our study was the first to describe barriers to physical activity in physically active adults before the COVID-19 pandemic. In our sample, more than $60 \%$ of participants indicated that COVID-19 pandemic influenced severely in their physical activity levels. Because of low physical activity levels, individuals may experience an increased risk for the development or worsening of health conditions as weight gain, high blood pressure, glycemic and lipid control and impaired fitness [36, 37]. Additionally, moderate intensity physical activity has been recommended as a non-pharmacological, inexpensive, and viable way to cope with COVID-19 virus, also due to the benefits on the immune system and its ability to reduce systemic inflammation $[13,38]$.

Personal barriers such as "laziness and fatigue", "lack of motivation", and "lack of time" were the most prevalent. Interestingly, these barriers were identified previously in clinical populations $[15,18]$ and healthy $[19,20]$ before the COVID-19 pandemic. However, some results were somewhat surprising, given that individuals are probably under social isolation, lack of time or laziness and/or fatigue were not expected as the most prevalent personal barriers. On the other hand, both lack of time and laziness and/or fatigue could be associated with domestic activities and working at home, which would need to be further investigated. Previous studies $[19,39]$ have shown that both lack of time and fatigue are prevalent barriers in the population.

Lack of appropriate facilities/equipment/space was the most reported environmental barrier to physical activity and was associated with affecting physical activity levels due to the COVID-19. Therefore, it is possible to assume that many individuals under social isolation do not consider the home as an environment conducive to physical activity [14]. As closures of parks, trails, gyms and beaches make it

Table 2 Frequency of reported barriers to physical activity of women and men during COVID-19 pandemic

\begin{tabular}{|c|c|c|c|c|}
\hline Variables & All & Male & Female & $p$ \\
\hline Laziness, fatigue & $50.2(47.7-52.7)$ & $48.1(44.4-51.8)$ & $51.8(48.5-55.1)$ & 0.145 \\
\hline Lack of motivation & $31.2(29.0-33.6)$ & $30.1(26.8-33.7)$ & $32.1(29.1-35.3)$ & 0.388 \\
\hline Lack of appropriatefacilities/equipment/space & $18.0(16.2-20.0)$ & $15.1(12.6-17.9)$ & $20.3(17.8-23.1)$ & 0.007 \\
\hline Lack of time & $13.0(11.5-14.8)$ & $13.5(11.1-16.7)$ & $12.8(10.8-15.2)$ & 0.718 \\
\hline Weather & $9.4(8.1-11.0)$ & $10.4(8.3-12.9)$ & $8.8(7.1-10.8)$ & 0.283 \\
\hline Lack of partner & $9.2(7.8-10.7)$ & $9.1(7.1-11.5)$ & $9.3(7.6-11.1)$ & 0.843 \\
\hline Pain, injury or I am not able to do & $8.5(7.2-9.9)$ & $7.9(6.1-10.2)$ & $8.9(7.3-11.1)$ & 0.426 \\
\hline I have no way to commute for exercising & $7.4(6.4-9.0)$ & $7.2(5.5-9.3)$ & $8.0(6.4-9.9)$ & 0.529 \\
\hline It is not fun & $6.3(5.2-7.6)$ & $6.0(4.5-8.0)$ & $6.6(5.2-8.5)$ & 0.588 \\
\hline Need to relax and rest & $5.3(4.3-6.6)$ & $5.8(4.3-7.9)$ & $5.1(3.8-6.7)$ & 0.503 \\
\hline Lack of Money & $3.0(2.3-4.0)$ & $3.4(2.3-5.0)$ & $2.8(1.9-4.1)$ & 0.542 \\
\hline Lack of competence & $2.7(2.0-3.6)$ & $2.8(1.8-4.3)$ & $2.7(1.8-4.0)$ & 0.952 \\
\hline Fear of injuries & $1.8(1.2-2.6)$ & $1.8(1.0-3.0)$ & $1.9(1.2-3.0)$ & 0.775 \\
\hline Lack of support & $1.7(1.2-2.5)$ & $2.0(1.2-3.4)$ & $1.6(0.9-2.6)$ & 0.496 \\
\hline I do not understand why it is important & $1.5(1.0-2.3)$ & $1.3(0.7-2.5)$ & $1.8(1.1-2.9)$ & 0.399 \\
\hline Body shame & $0.8(0.5-1.4)$ & $1.0(0.5-2.1)$ & $0.8(0.4-1.6)$ & 0.645 \\
\hline
\end{tabular}

Data are present as frequency $(95 \%$ confidence interval) 
Table 3 Adjusted binary logistic regression modeling for the association between barriers to physical activity and impact on physical activity level due to the COVID-19 pandemic

\begin{tabular}{lllr}
\hline & OR & $95 \%$ CI & $p$ \\
\hline Laziness, fatigue & 1.15 & $0.94-1.42$ & 0.170 \\
Lack of motivation & 1.49 & $1.19-1.86$ & $<0.001$ \\
$\begin{array}{l}\text { Lack of appropriate facili- } \\
\text { ties/equipment/space }\end{array}$ & 2.10 & $1.57-2.83$ & $<0.001$ \\
Lack of time & 1.16 & $0.87-1.56$ & 0.321 \\
\hline
\end{tabular}

Adjusted for sex, education level, status weight, age, type of residence, and days of social isolation

OR odds ratio, $95 \%$ CI $95 \%$ confidence interval

more difficult for individuals to be active, it is important that health professionals should provide information to population about different possibilities of home exercise programs [40-42].

Lack of motivation was the second most prevalent barrier in the current study, although in relative terms it was less than other studies conducted before the pandemic. Herazo-Beltrán et al. [19], analyzed 2102 Colombians and observed that $54.6 \%$ reported lack of motivation as a barrier, compared with $30.1 \%$ in this study. However, this barrier also was associated with affecting physical activity levels due to the COVID-19. Some recommendations to overcome this barrier are invite a friend to exercise with you on a regular basis and write it on both your calendars and join an exercise group or class [43]. However, due to social isolation these alternatives are not possible. On the other hand, make physical activity a regular part of your daily or weekly schedule and write it on your calendar or exercising with relatives can be options.

This study has limitations that are worth highlighting. The cross-sectional design of this study is an evident limitation because no causality can be inferred. Additionally, online surveys are susceptible to information and social biases. Furthermore, rather than spontaneously reporting barriers through open-ended questions, dichotomous questions were created which may have limited the scope of responses. However, this was necessary to conduct our analyses. Due to the high number of barriers, we analyzed in binary logistic regression only those with a prevalence $\geq 10 \%$, whose value was arbitrary. Finally, the measurement of physical activity before the COVID-19 pandemic did not take into consideration volume and intensity. However, our study's large sample size and its timely assessment of health behaviors makes our findings important and quite relevant.

In conclusion, "Laziness and fatigue", "lack of motivation", "lack of appropriate facilities/equipment/space" and "lack of time" were the barriers most reported. In addition, "lack of motivation" and "lack of appropriate facilities/equipment/space" were most associated barriers with decreased physical activity levels due to COVID- 19 . These results add important information that could support police markers to develop effective public policies to reduce the jeopardizing effects of stay-at-home orders during the COVID-19 pandemic.

Author contributions BQF conceptualized and designed the study, carried out the analyses and drafted the initial manuscript. WLdP designed the data collection instruments, coordinated and supervised data collection, reviewed the manuscript. NM contributed to the interpretation of the data, and reviewed the manuscript. MCL-P contributed to the interpretation of the data, and reviewed the manuscript. PHdM contributed to the interpretation of the data, and reviewed the manuscript. JPB contributed to the interpretation of the data, and reviewed the manuscript. GGC conceptualized and designed the study, and reviewed the manuscript. MAC conceptualized and designed the study, and reviewed the manuscript. RMR-D designed the data collection instruments, coordinated and supervised data collection, conceptualized and designed the study, and reviewed the manuscript. All authors approved the final manuscript as submitted and agree to be accountable for all aspects of the work.

Funding The authors have no financial relationships relevant to this article to disclose. Wagner L. Prado is supported by ASPIRE grants (\# UC2 GM137444-02).

\section{Compliance with ethical standards}

Conflict of interest The authors declare that there are no conflicts of interest. BQ Farah was responsible for starting the writing of the manuscript. In addition, no person received any honorarium, grant, or other form of payment to produce the manuscript.

Ethical approval The study was approved by the University Nove de Julho (\#30890220.4.0000.5511 approved on May 1st 2020) and complies with the guidelines of both the Brazilian National Research Ethics System as well as the Helsinki declaration of 1975 (revised in 1983).

Informed consent All participants signed an informed consent form.

\section{References}

1. Hellewell J, Abbott S, Gimma A, Bosse NI, Jarvis CI, Russell TW et al (2020) Feasibility of controlling COVID-19 outbreaks by isolation of cases and contacts. Lancet Global health 8(4):e488-e496

2. Hall G, Laddu DR, Phillips SA, Lavie CJ, Arena R (2021) A tale of two pandemics: how will COVID-19 and global trends in physical inactivity and sedentary behavior affect one another? Progress Cardiovasc Dis 64:108-110

3. Burtscher J, Burtscher M, Millet GP (2020) (Indoor) isolation, stress and physical inactivity: vicious circles accelerated by Covid-19? Scand J Med Sci Sports 30(8):1544-1545

4. Chen P, Mao L, Nassis GP, Harmer P, Ainsworth BE, Li F (2020) Coronavirus disease (COVID-19): the need to maintain regular physical activity while taking precautions. J Sport Health Sci 9(2):103-104

5. Lee IM, Shiroma EJ, Lobelo F, Puska P, Blair SN, Katzmarzyk PT et al (2012) Effect of physical inactivity on major 
non-communicable diseases worldwide: an analysis of burden of disease and life expectancy. Lancet 380(9838):219-229

6. Ozemek C, Lavie CJ, Rognmo O (2019) Global physical activity levels - need for intervention. ProgCardiovasc Dis 62(2):102-107

7. Ashton RE, Tew GA, Aning JJ, Gilbert SE, Lewis L, Saxton JM (2020) Effects of short-term, medium-term and long-term resistance exercise training on cardiometabolic health outcomes in adults: systematic review with meta-analysis. Br J Sports Med 54(6):341-348

8. Hidayat K, Zhou HJ, Shi BM (2020) Influence of physical activity at a young age and lifetime physical activity on the risks of 3 obesity-related cancers: systematic review and meta-analysis of observational studies. Nutr Rev 78(1):1-18

9. Patterson R, Panter J, Vamos EP, Cummins S, Millett C, Laverty AA (2020) Associations between commute mode and cardiovascular disease, cancer, and all-cause mortality, and cancer incidence, using linked Census data over 25 years in England and Wales: a cohort study. Lancet Planet health 4(5):e186-e194

10 Zhao M, Veeranki SP, Magnussen CG, Xi B (2020) Recommended physical activity and all cause and cause specific mortality in US adults: prospective cohort study. BMJ 370:m2031

11. World Health Organization (2020) Stay physically active during self-quarantine. In: Europe WHO-ROf. World Health Organization, Geneva

12. American College of Sports Medicine (2020) Staying active during the coronavirus pandemic. American College of Sports Medicine, New York

13. Pecanha T, Goessler KF, Roschel H, Gualano B (2020) Social isolation during the COVID-19 pandemic can increase physical inactivity and the global burden of cardiovascular disease. Am J Physiol Heart CircPhysiol 318(6):H1441-H1446

14. Gallo LA, Gallo TF, Young SL, Moritz KM, Akison LK (2020) The impact of isolation measures due to COVID-19 on energy intake and physical activity levels in Australian university students. Nutrients 12(6)

15. Barbosa JP, Farah BQ, Chehuen M, Cucato GG, Farias Junior JC, Wolosker $\mathrm{N}$ et al (2015) Barriers to physical activity in patients with intermittent claudication. Int J Behav Med 22(1):70-76

16. Booth ML, Bauman A, Owen N, Gore CJ (1997) Physical activity preferences, preferred sources of assistance, and perceived barriers to increased activity among physically inactive Australians. Prev Med 26(1):131-137

17. Silva KS, Del Duca GF, Garcia LM, da Silva JA, Bertuol C, de Oliveira ES et al (2016) Barriers associated with frequency of leisure-time physical activity among Brazilian adults of different income strata. Scand J Med Sci Sports 26(2):206-213

18. Cavalcante BR, Farah BQ, Barbosa JPA, Cucato GG, da Rocha CM, da Silva SF et al (2015) Are the barriers for physical activity practice equal for all peripheral artery disease patients? Arch Phys Med Rehabil 96(2):248-252

19. Herazo-Beltran Y, Pinillos Y, Vidarte J, Crissien E, Suarez D, Garcia R (2017) Predictors of perceived barriers to physical activity in the general adult population: a cross-sectional study. Braz $\mathrm{J}$ PhysTher 21(1):44-50

20. Justine M, Azizan A, Hassan V, Salleh Z, Manaf H (2013) Barriers to participation in physical activity and exercise among middle-aged and elderly individuals. Singap Med J 54(10):581-586

21. Speretta GF, Leite RD (2020) Covid-19: high rates of severity and death in elderly and patients with chronic diseases reinforces the importance of regular physical activity. Sport Sci Health 1-2

22. von Elm E, Altman DG, Egger M, Pocock SJ, Gotzsche PC, Vandenbroucke JP et al (2007) The Strengthening the Reporting of Observational Studies in Epidemiology (STROBE) statement: guidelines for reporting observational studies. Lancet 370(9596):1453-1457
23. Lesser IA, Nienhuis CP (2020) The impact of COVID-19 on physical activity behavior and well-being of Canadians. Int J Environ Res Public Health 17(11):3899

24. Ruiz-Roso MB, de Carvalho Padilha P, Matilla-Escalante DC, Brun P, Ulloa N, Acevedo-Correa D et al (2020) Changes of physical activity and ultra-processed food consumption in adolescents from different countries during Covid-19 pandemic: an observational study. Nutrients 12(8):2289

25. Maugeri G, Castrogiovanni P, Battaglia G, Pippi R, D’Agata V, Palma A et al (2020) The impact of physical activity on psychological health during Covid-19 pandemic in Italy. Heliyon 6(6): $\mathrm{e} 04315$

26. Da Cunha de Sa-Caputo D, Sonza A, Bachur JA, Bernardo-Filho M (2020) Development, validation and reliabilty of a questionnaire to evaluate the changes on the level of physical exercises and in daily life habits due to COVID-19 pandemic social distancing. Acta Bio-medicaAteneiParmensis. 91(3):e2020004

27. Toledano-Toledano F, Rodriguez-Rey R, Moral-de-la-Rubia J, Luna D (2019) A Sociodemographic variables questionnaire (Q-SV) for research on family caregivers of children with chronic disease. BMC Psychol 7(1):85

28. Pedreira RB, Rocha SV, Santos CA, Vasconcelos LR, Reis MC (2016) Content validity of the Geriatric Health Assessment Instrument. Einstein 14(2):158-177

29. de Sousa ASA, Correia MA, Farah BQ, Saes G, Zerati AE, PuechLeao $P$ et al (2019) Barriers and levels of physical activity in patients with symptomatic peripheral artery disease: comparison between women and men. J Aging Phys Act 27(5):719-724

30. Farah BQ, Andrade-Lima A, Germano-Soares AH, Christofaro DGD, de Barros MVG, do Prado WL et al (2018) Physical activity and heart rate variability in adolescents with abdominal obesity. PediatrCardiol 39(3):466-472

31. da Cunha-Silva-Santiago L, Batista RM, Lyra MJ, Farah BQ, Pedrosa RP, Falcao AP et al (2017) The role played by gender and age on poor sleep quality among institutionalized adolescents. Sleep Breath 21(1):197-202

32. Quintella Farah B, Silva Rigoni VL, de Almeida CM, Wolosker N, Puech-Leao P, GrizzoCucato G et al (2019) Influence of smoking on physical function, physical activity, and cardiovascular health parameters in patients with symptomatic peripheral arterial disease: A cross-sectional study. J VascNurs 37(2):106-112

33. Bowring AL, Peeters A, Freak-Poli R, Lim MS, Gouillou M, Hellard M (2012) Measuring the accuracy of self-reported height and weight in a community-based sample of young people. BMC Med Res Methodol 12:175

34. World Health Organization (2010) Global recommendations on physical activity for health. In: activity WTP, editor. World Health Organization, Genebra

35. Matias T, Dominski FH, Marks DF (2020) Human needs in COVID-19 isolation. J Health Psychol 25(7):871-882

36. Chastin SFM, De Craemer M, De Cocker K, Powell L, Van Cauwenberg J, Dall P et al (2019) How does light-intensity physical activity associate with adult cardiometabolic health and mortality? Systematic review with meta-analysis of experimental and observational studies. Br J Sports Med 53(6):370-376

37. Paudel S, Owen AJ, Owusu-Addo E, Smith BJ (2019) Physical activity participation and the risk of chronic diseases among South Asian adults: a systematic review and meta-analysis. Sci Rep 9(1):9771

38. Rahmati-Ahmadabad S, Hosseini F (2020) Exercise against SARS-CoV-2 (COVID-19): does workout intensity matter? A mini review of some indirect evidence related to obesity. Obes Med 100245

39. Cerin E, Leslie E, Sugiyama T, Owen N (2010) Perceived barriers to leisure-time physical activity in adults: an ecological perspective. J Phys Act Health 7(4):451-459 
40. Nilsson MI, Mikhail A, Lan L, Di Carlo A, Hamilton B, Barnard K, et al. (2020) A five-ingredient nutritional supplement and home-based resistance exercise improve lean mass and strength in free-living elderly. Nutrients 12(8)

41. Connolly LJ, Scott S, Morencos CM, Fulford J, Jones AM, Knapp $\mathrm{K}$ et al (2020) Impact of a novel home-based exercise intervention on health indicators in inactive premenopausal women: a 12-week randomised controlled trial. Eur J ApplPhysiol 120(4):771-782

42. Schwendinger F, Pocecco E (2020) Counteracting physical inactivity during the COVID-19 pandemic: evidence-based recommendations for home-based exercise. Int J Environ Res Public Health 17(11)
43. Centers for Disease Control and Prevention (2020) Suggestions for overcoming physical activity barriers. In: Division of Nutrition PA, and Obesity, National Center for Chronic Disease Prevention and Health Promotion, editor, Centers for Disease Control and Prevention

Publisher's Note Springer Nature remains neutral with regard to jurisdictional claims in published maps and institutional affiliations. 